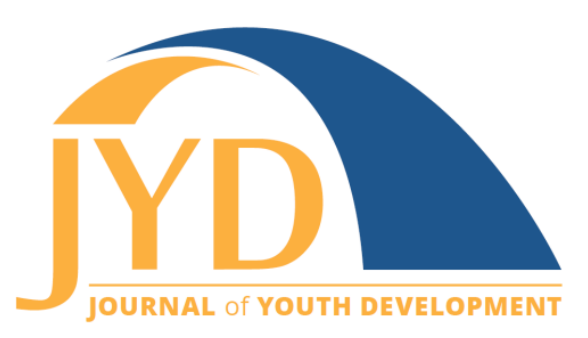

http://jyd. pitt. edu/ | Vol. 14 Issue 4 DOI 10.5195/jyd.2019.727 | ISSN 2325-4017 (online)

\title{
Does Equine Assisted Learning Create Emotionally Safe Learning Environments for At-Risk Youth?
}

\author{
Katie Cagle-Holtcamp \\ Mississippi State University \\ kac325@msstate.edu \\ Molly Christine Nicodemus \\ Mississippi State University \\ mnicodemus@ads.msstate.edu \\ Julie Parker \\ Mississippi State University \\ jparker@humansci.msstate.edu \\ Mattie Helen Dunlap \\ Mississippi State University \\ mhd94@msstate.edu
}

\begin{abstract}
Equine assisted learning (EAL) is a form of experiential learning that is quickly growing in interest within the educational community. A challenge with experiential learning programs for at-risk youth is creating an emotionally safe environment that opens up the participants to learning. Nevertheless, EAL has been credited with the development of life skills in youth that promote educational achievement, but research tracking the development of emotional safety and learning, specifically associated with programming dedicated to educating participants about the horse, is limited. Therefore, the objective of this study was to determine if EAL, with programming centered around equine education, will promote emotional safety and learning in at-risk youth. Youth labeled as at-risk participated in a 4-week EAL session focused on teaching participants horse behavior, management, handling, and riding, while incorporating the 4 themes of emotional safety (self-esteem, personal security, respect, and connectivity). To determine participant learning of the equine topics covered, a pre- and post-program test was given to each participant. Acquirement of the themes of emotional safety was tracked for each participant using weekly debriefing interviews. While this was the first time to perform this assessment protocol for evaluating learning and emotional safety in at-risk youth, the completion rate for both forms of assessment utilized in this study was $100 \%$. Evaluation of debriefing interview answers and test scores from the equine
\end{abstract}

(cc) EY New articles in this journal are licensed under a Creative Commons Attribution 4.0 License. This journal is published by the University Library System, University of Pittsburgh and is cosponsored by the University of Pittsburgh Press. The Journal of Youth Development is the official peer-reviewed publication of the National Association of Extension 4-H Agents and the National AfterSchool Association. 
Equine Assisted Learning and Emotional Safety

knowledge questions showed improvement by the end of the session in both equine knowledge and emotional safety, particularly as it relates to personal security. These results suggest EAL, with programming directed towards educating the participant about the horse, promotes emotional safety and learning for at-risk youth.

Key words: equine assisted learning, emotional safety, at-risk youth, equine therapy

\section{Introduction}

High school and college-aged youth, age 16 to 24 years old, who are currently idle (neither in school nor employed) make up 1 in 9 youth in the United States (McCann, 2018). Identifying those youth that are at-risk of becoming a part of this statistic is critical to educators. At-risk youth are youth who have been exposed to risk factors in childhood that correlate to negative outcomes in the following years (Burgon, 2014). At-risk youth can typically be found with a montage of factors that lead to negative outcomes. Some of these include, but are not limited to, low self-esteem, poor social competency, decreased coping skills, and inappropriate responses to relational stimuli. For at-risk youth, a classroom that doesn't create a safe environment for the youth's emotions hinders their learning potential and this can have a permanent impact on their academic future (Heid, 2018; Reilly, 2018), thus, emphasizing the importance of an effective therapeutic intervention (Kendall \& Maujean, 2015). Traditionally, talk-therapy has been recommended to these individuals in hopes of working through the challenges that they face from home, school, and their communities (Paone, Packman, Maddox, \& Rothman, 2008). Unfortunately, talk-therapy has not shown reliable, consistent results; therefore, the problem continues to intensify (Harris, 2011; Ruiz, 2012).

Animal therapy using an animal as the therapy tool is a form of experiential therapy (Nicodemus, 2019; Oaklander, 2018). Experiential therapy is defined as an opportunity that encourages participants to work through repressed or subconscious problems by means of active experiences (Wilson \& Lipsey, 2000). These services can be offered in a variety of ways such as horseback riding along with other activities including yoga, meditation, recreational therapy, and ropes course challenges. Outdoor experiential programming can often act as groundwork for positive development in youth (Buning, Coble, \& Kerwin, 2015; Henderson, Whitaker, Bialeschki, Scanlin, \& Thurber, 2007; Saunders-Ferguson, Barnett, Culen, \& TenBroneck, 2008).

Equine assisted learning (EAL), a form of animal therapy, is newer on the experiential therapy option list for treatment of emotional and behavioral issues, and yet, it has demonstrated 
Equine Assisted Learning and Emotional Safety

positive impacts for clients, such as at-risk youth, who may not respond to traditional therapies (Bachi, Terkel, \& Teichman, 2012; Brandt, 2013). In particular, according to Lentini \& Knox (2015), this form of treatment lends itself well to youth that have become "counselor-wise," such as those diagnosed with oppositional defiant disorder where the youth responds in a more strategic manner concealing their true feelings and emotions from the therapist. EAL, on the other hand, is set in a non-traditional therapy environment that uses the horse as a tool to provide a learning opportunity to advance life skills for personal and educational achievement (Lutz, 2010; Professional Association of Therapeutic Horsemanship International [PATH Intl.], 2017). According to PATH Intl. (2017), EAL is described as "an experiential learning approach that promotes the development of life skills for educational, professional, and personal goals through equine-assisted activities" (Equine-Assisted Learning [EAL], para. 1). These activities can be performed either on horseback or on the ground and can be set as a group activity or on an individual basis depending on the client's needs. While this is a relatively new treatment option, studies have reported that through EAL social communication became easier and social comprehension increased (Bass, Duchowny, \& Llabre, 2009; Ward, Whalon, Rusnak, Wendell, \& Paschall, 2013). Furthermore, the effects felt during individual EAL sessions have been found to infiltrate the participant's daily life (Benton, Petr, Schneider, \& Ivey, 2019; Ward et al., 2013).

Equine assisted therapy opportunities such as EAL have been shown to increase treatment attendance and engagement (Brandt, 2013). This form of therapy is thought to hold the potential for reaching a more diverse population than traditional therapies that allow for community-based programming with the opportunity of serving whole families (Lentini \& Knox, 2015; Letiecq, Bailey, \& Keller, 2007). Specifically, according to Lentini \& Knox (2015), this form of therapy has demonstrated success in youth diagnosed with eating disorders, autism, attention deficit hyperactivity disorder, depression, anxiety, and post-traumatic stress disorder. The approach taken with equine assisted therapy is thought to lend itself to at-risk populations due to the targeting of specific environmental risk factors associated with at-risk youth (Geller \& Porges, 2014; Ryon, Early, \& Kosloski, 2017). The farm environment where the therapy takes place is set away from the typical negative environments that these youth come from allowing them to see their struggles from a different point of view (Lentini \& Knox, 2015). Though research is limited and mostly based off of anecdotal evidence, practitioners at the Cincinnati Children's Hospital Medical Center continue to support this type of therapy to children with mental health and self-esteem challenges. The support for this therapy, according to Lentini \& Knox (2015), is attributed to the fact that the EAL activities promote the teaching of "structure, responsibility, routine, care for another (the horse), empathy, safe mistake-making, the value of practice and mastery, discipline, problem solving, body awareness, visual learning, patience, 
Equine Assisted Learning and Emotional Safety

respect for others' choices, creativity, self-esteem, relaxation, the value of completing necessary but unpleasant tasks, self-reflection, and nurturing" (p.53).

Nevertheless, while EAL activities lend themselves to the successful treatment of at-risk youth, a limitation to EAL is the lack of evidence-based programming needed to show significant, longlasting improvement in these youth (Lentini \& Knox, 2015). Although most are in agreement that this type of therapy can be useful for treatment of a variety of populations as it can host a multitude of lessons and activities, little agreement is present among practitioners on best practices that are specific to a diagnosis (Brandt, 2013). Previously, practitioners have focused on the therapeutic aspect of using the horse as a therapy tool, rather than the goal of educating the therapy participant about the basic principles of equine sciences including horse behavior, management, handling, and riding (Maujean, Kendall, Lillan, Sharp, \& Pringle, 2013). Traditionally, therapeutic tools addressed in a child therapy session aren't addressed in an educational format beyond just self-exploration (Hall, Schaefer, \& Kaduson, 2002). For example, in a child therapy session using art supplies as a tool for self-expression, the therapist typically won't teach the child techniques on brush strokes and shading nor proper ways to hold the colored pencils or paint brushes, but instead, will focus on the child freely drawing or painting to express their emotions. In contrast, the use of the horse brings about a unique challenge to the therapist as, unlike other traditional tools used in therapy, the therapy horse creates safety issues due to its size and flight response. If participants are not educated about instinctive responses of the horse and safe, proper handling techniques, they can be put in danger of getting hurt. This, nevertheless, provides a unique opportunity for learning for children with cognitive, behavioral or emotional difficulties (Benton et al., 2019) that, in turn, can build both knowledge and confidence within the participant (Evans et al., 2019). Understanding how to properly handle a large animal is useful to prevent potential accidents, and can also be empowering to the youth (Lentini \& Knox, 2015).

A main variable in EAL is the design of the delivery (Brandt, 2013; Odendaal, 2000). Though the sessions are often presented in a group format, each participant typically works with a single horse one-on-one. Each session follows a strict itinerary in order to maintain structure and consistency, allowing participants to feel more comfortable and accepting since they know what to expect. Activities that have this type of design have been proven effective for individuals with emotional connectivity problems such as those youths categorized as at-risk (Borgi et al., 2016). The routine creates an environment that contributes to positive bonding and communication development, thus, creating an environment of emotional safety. Emotional safety as defined by the National Center for Safe Supportive Learning Environments (2018) is 
Equine Assisted Learning and Emotional Safety

"an experience in which one feels safe to express emotions, security, and confidence to take risks and feel challenged and excited to try something new" (Emotional Safety, para. 1). In previous studies with equine assisted activities, college students have shown improvement in themes reflecting emotional safety (respect, connectivity, personal security, and self-esteem; Cagle-Holtcamp et al., 2019; Evans et al., 2019; Hammer et al., 2019), but similar research concerning at-risk youth is unavailable at this time.

Due to a lack of literature on the effectiveness of EAL for at-risk youth, particularly those programs focused on educating the youth concerning the basics of equine science (horse behavior, management, handling, and riding), not much is known about expected results of this treatment for this population. Therefore, the objective of this study was to determine if EAL with a focus on educating the youth about the horse creates an emotionally safe environment that promotes learning in at-risk youth. The goal was to create emotional safety in at-risk youth through EAL so that the participants are able to learn about the horse.

\section{Materials and Methods}

\section{Sampling and Population}

All procedures for the study followed guidelines according to the Institutional Review Board (IRB). The population for this study consisted of participants recruited through purposive sampling. Purposive sampling was used to identify individuals from an applicant pool meeting the following criteria: living under the poverty line, accepting reduced-price or free lunch at school, minority, having a history of criminality, and/or having a history of abuse. Applicants meeting the above criteria were recruited by utilizing school counselors, child protective service employees, and justice department employees. The rationale for selecting based on the above criteria was to guarantee the participants fell under at-risk guidelines (Hopper \& Iwasaki, 2017; Burgon, 2011). Specifically, researchers contacted case workers by phone for Child Protective Services in Oktibbeha, Clay, and Monroe counties in Mississippi to make an appointment to discuss participation details. Meetings were held at each facility to talk about program benefits, time commitment, application process, program goals, and research methods. The Tribal Justice System of Philadelphia, Mississippi was also contacted and given the same information via telephone. These organizations were chosen due to being in at-risk youth populous areas defined by meeting rural community standards established by Mississippi Child Protective Services. Applications for participation in the EAL program were delivered in person, emailed, faxed, or mailed to each organization. Once these organizations were educated concerning the 
research project, representatives of the organizations assisted in the recruitment of participants and successful completion and submission of the participant applications for the study. A total of 13 youths (ages 6 to 16 years) classified as at-risk according to the guidelines were recruited for the 4-week EAL program including participation in the quantitative and qualitative analysis described below. These youths were the only youths that participated in the EAL program at the time of the study.

\section{Data Collection}

This study defined treatment as the participation for 4 weeks in EAL activities that were aimed at targeting at-risk youths' emotional safety (National Center for Safe Supportive Learning Environments, 2018). This variable was measured using an activity log to record the activities and amount completed versus those EAL activities planned. The EAL instructors used a selfreporting system for monitoring curriculum content compliance to ensure each requirement was taught. The reporting system documented what each participant did for each EAL lesson and whether the goals for that day were achieved by each participant. Following IRB guidelines, prior to the start of the EAL program, parents and their children were made aware that all activities associated with this study-including equine activities, knowledge testing, and debriefing interviews-were voluntary, so that participation in any aspect of this study was optional for the youth. A lack of participation in any aspect of the study would not result in the dismissal of the participant from the program. At no time was a participant forced to participate in any activity associated with this study.

Each lesson was planned prior to the program implementation using the Eagala Model (Thomas, Lytle, \& Dammann, 2016). This model was selected as Eagala "was one of the first to develop a concrete model of professional standards for incorporating horses into mental health treatment" (Eagala, 2019, Our History, para. 1). This model was the only model at the time that outlined specific lesson plans for the population being addressed within this study, which, in turn, allowed for repeatability of the study. Instructors for the EAL program were Eagala certified. The lessons were divided into a cognitive knowledge section focusing on basics of equine science as it relates to horse behavior, management, handling, and riding (Certified Horsemanship Association [CHA], 2008); practical activities aimed at self-awareness (Thomas et al., 2016); and time for daily processing. Table 1 gives a brief overview of the themes and activities for each week covered in the EAL session. This program was held in the Northeast region of Mississippi at a PATH, Intl. certified equine assisted therapy center operated by Mississippi State University. 
Equine Assisted Learning and Emotional Safety

Table 1. Equine Assisted Learning 4-Week Program Themes and Activities for AtRisk Youth

\begin{tabular}{|l|l|l|}
\hline Week & Programming theme & Equine activity \\
\hline 1 & Respect & Catching and leading horse \\
\hline 2 & Connectivity & Grooming and ground handling horse \\
\hline 3 & Personal security & Introduction to horse riding \\
\hline 4 & Self-esteem & Advanced riding skills \\
\hline
\end{tabular}

\section{Equine Knowledge}

This study measured equine science knowledge-the fundamental skills or understanding that beginner students would learn at the first level of equine instruction (CHA, 2008)-through a pretest/posttest methodology (Table 2). The pretest was administered on the first day of the 4week EAL session. The participants were given unlimited time to complete the test. Any individual who needed clarification or technical assistance with the test was provided help by the instructor, but was not provided any indication of the correct answer. An untimed, identical posttest was given at the end of the last lesson. The same instructor provided assistance where needed. The test contained 35 questions gathered from 4-H horse bowl trivia (AgriLife Extension, 2013) and a beginner equine instructional book (CHA, 2008). Questions 1 through 23 were established as multiple choice questions with an option of four choices and questions 24 through 35 were true/false questions. Each item on the test (see Table 1) was taught over the course of the program in equine science educational segments. This portion of the method was completed to fulfill an educational hierarchy of needs. Students could not be held accountable for intervention engagement without basic understanding of equine behavior and how to safely interact and handle the horse.

For protection of participant records, the tests were coded to keep participant identification confidential and were taken to the principle investigator's (PI) office where the tests and the key to the coding system were locked in a secure cabinet, except during active analysis. Tests were accessible to the research team only under the supervision of the PI. The coding key was not accessible to anyone, but the PI. 
Table 2. Questions From the Equine Knowledge Pre- and Post-Program Tests

\begin{tabular}{|c|c|}
\hline No. & Knowledge question \\
\hline 1 & How high is a hand? \\
\hline 2 & What are the horse's hooves made of? \\
\hline 3 & What are the two styles of riding? \\
\hline 4 & What is the part of the saddle that goes under the horse's belly called? \\
\hline 5 & What side of the horse should you mount from? \\
\hline 6 & What is the part of the saddle that comes up highest behind the rider's seat? \\
\hline 7 & What is the part of the halter that lies behind a horse's ears and is usually buckled into place? \\
\hline 8 & What is a white marking on a horse's forehead? \\
\hline 9 & What is a mare? \\
\hline 10 & What is a gelding? \\
\hline 11 & What is a filly? \\
\hline 12 & What is a colt? \\
\hline 13 & What is a stallion? \\
\hline 14 & What is a foal? \\
\hline 15 & What is the flank? \\
\hline 16 & How do you tell a horse and a pony apart? \\
\hline 17 & How many times should you water a horse per day? \\
\hline 18 & What will a frightened horse do first? \\
\hline 19 & What should a horse be tied with? \\
\hline 20 & How do you lead a horse safely? \\
\hline 21 & Where should your eyes be focused when riding? \\
\hline 22 & What command do you use to stop your horse? \\
\hline 23 & Where do you approach your horse from? \\
\hline 24 & Horses learn through reward and punishment. \\
\hline 25 & A horse can pay attention to reward and punishment for three minutes. \\
\hline 26 & A walk is a three beat gait. \\
\hline 27 & A trot is a two beat gait. \\
\hline 28 & A horse should be tied with a quick release knot. \\
\hline 29 & Clothes you wear to ride in are important. \\
\hline 30 & When riding, your heels are up and your toes are down. \\
\hline 31 & Speaking to your horse on approach is not necessary. \\
\hline 32 & You should never wrap the lead rope around your hand or arm. \\
\hline
\end{tabular}


Table 2 (continued)

\begin{tabular}{|l|l|}
\hline No. & Knowledge question \\
\hline 33 & You can be bitten while feeding horses treats. \\
\hline 34 & A soft brush is used to remove loose dirt from the horse's coat. \\
\hline 35 & A hoof pick is used to clean dirt from the horse's hoof. \\
\hline
\end{tabular}

\section{Participant Interviews}

Semi-structured interviews were conducted at the conclusion of each session. First week interviews were administered as a group discussion to encourage more thorough and forthcomings responses. Individual interviews were conducted for the remainder of the weeks of the session. The questions were chosen before the program began and were asked exactly as written (Table 3). Questions came from previous research evaluating emotions and behaviors of youth participating in equine assisted therapy programming (Burgon, 2014). As shown in Table 3, each weekly interview consisted of five questions asked of each participant. The participants were asked a series of predetermined questions based on the daily lessons, how they felt, what they learned, and how the information could affect daily life outside of the equine environment.

For all interviews, the instructor would ask a question, give the participant time to think about it, and record everything the participant said verbatim. Additional documentation was made concerning the tone of the responses during the interview. To clarify answers given during the interview process, participants were encouraged to give specific examples of activities they performed that may have related back to the emotional safety themes (Table 4). All responses were typed into a Microsoft Excel 2013 spreadsheet as the individual was speaking, and coded for confidentiality. All interview notes and the file with responses were stored and accessed only by the PI.

Researchers used a self-reporting methodology for participant responses (Short et al., 2009). Responses were organized and classified by the same trained observer under four themes from the language used in the responses: self-esteem, connectivity, respect, and personal security (see Table 4 for examples of responses and classification by theme). A second analyst assisted in organizing themes of responses while looking at a blind copy of the interview responses to minimize bias. Identification of these themes along with the key language of the responses was 
selected based on previous research (Bird, 1996; Crocker, Luhtanen, Cooper, \& Bouvrette, 2003; Kagan, 2009).

\section{Table 3. Questions From the Participant Interviews}

\begin{tabular}{|c|c|c|}
\hline Week & No. & Interview question \\
\hline \multirow[t]{5}{*}{1} & 1 & What do you think about horses? \\
\hline & 2 & How do you think horses like us to treat them and behave around them? \\
\hline & 3 & How do horses tell you about your mood? \\
\hline & 4 & Do you think that our behavior affects the horses? If so, how? \\
\hline & 5 & $\begin{array}{l}\text { Which horse would you like to be like? What is it about that horse that you want to } \\
\text { be like? }\end{array}$ \\
\hline \multirow[t]{5}{*}{2} & 6 & Do you think these horse lessons could be applied to other parts of your life? \\
\hline & 7 & Do you have a favorite horse? What is it about the horse that you like? \\
\hline & 8 & How would you describe your horse's personality? \\
\hline & 9 & Do you think that horse notices your moods? How can you tell? \\
\hline & 10 & $\begin{array}{l}\text { Does being around horses change your mood or make you feel differently? What is it } \\
\text { about the horses that changes how you feel? }\end{array}$ \\
\hline \multirow[t]{5}{*}{3} & 11 & Do you feel these equine lessons have been beneficial? If so, how? \\
\hline & 12 & What do you like doing best with this horse/any of the horses and why? \\
\hline & 13 & Is there anything specific you have learned from spending time with the horses? \\
\hline & 14 & What did you like best about today's activity? \\
\hline & 15 & How do you feel about yourself now that you have completed this activity? \\
\hline \multirow[t]{5}{*}{4} & 16 & $\begin{array}{l}\text { Do you notice any personal changes/differences in your behavior or mood after the } \\
\text { horse lessons? }\end{array}$ \\
\hline & 17 & Tell me what the most important thing you have learned about horses? \\
\hline & 18 & If you were telling someone else about what you did today what would you say? \\
\hline & 19 & Do you think horses are therapeutic? If so, why? \\
\hline & 20 & $\begin{array}{l}\text { Does being around horses change your mood or make you feel differently? If so, } \\
\text { what is it about the horse that changes how you feel? }\end{array}$ \\
\hline
\end{tabular}


Equine Assisted Learning and Emotional Safety

Table 4. At-Risk Youth Example Responses From Equine Assisted Learning Debriefing Interviews Organized by Emotional Safety Category

\begin{tabular}{|c|c|c|c|}
\hline Self-esteem & Personal security & Connectivity & Respect \\
\hline $\begin{array}{l}\text { "I conquered my fear of } \\
\text { riding the horse." }\end{array}$ & $\begin{array}{l}\text { "I feel relaxed and safe } \\
\text { around horses." }\end{array}$ & $\begin{array}{l}\text { "I can trust horses } \\
\text { and actually have a } \\
\text { bond with them." }\end{array}$ & $\begin{array}{l}\text { "My horse changes } \\
\text { my behavior by the } \\
\text { way he respects me." }\end{array}$ \\
\hline $\begin{array}{l}\text { "I was confident } \\
\text { approaching the } \\
\text { horse." }\end{array}$ & $\begin{array}{l}\text { "I feel more comfortable } \\
\text { with my horse." }\end{array}$ & $\begin{array}{l}\text { "I learned I am nice } \\
\text { because I am nice to } \\
\text { the horses." }\end{array}$ & $\begin{array}{l}\text { "The respect I learned } \\
\text { from my horse can } \\
\text { apply to other parts of } \\
\text { my life." }\end{array}$ \\
\hline $\begin{array}{l}\text { "I was in control of the } \\
\text { horse as I rode." }\end{array}$ & $\begin{array}{l}\text { "I moved away and } \\
\text { [horse] came up to me. } \\
\text { He did not want to hurt } \\
\text { me." }\end{array}$ & $\begin{array}{l}\text { "Horses listen to me. I } \\
\text { never feel heard." }\end{array}$ & $\begin{array}{l}\text { "My horse respects } \\
\text { me. I am not use to } \\
\text { being respected." }\end{array}$ \\
\hline $\begin{array}{l}\text { "I feel accomplished by } \\
\text { the end of the lesson." }\end{array}$ & $\begin{array}{l}\text { "I feel calm. This is a calm } \\
\text { place." }\end{array}$ & $\begin{array}{l}\text { "I have someone to } \\
\text { talk to when I am } \\
\text { with my horse." }\end{array}$ & $\begin{array}{l}\text { "Horses teach us to } \\
\text { be respectful." }\end{array}$ \\
\hline
\end{tabular}

\section{Statistical Analysis}

Scores for the equine knowledge tests were given as the number of answers correct out of the number of questions given, which was 35 questions for both tests. Mean scores $(M)$ and standard deviations $(S D)$ were determined for the equine knowledge pre- and post-program tests and for individual questions. A paired-samples t-test was conducted using IBM SPSS Statistics 24 (Armonk, NY) to compare the pretest and posttest overall scores and individual questions with statistical significance set at 0.05 .

Interview responses were classified into the four emotional safety themes (Table 4) with percentages of participants that demonstrated interview comments reflecting a theme were determined for each week. Means (SD) for the differences between the percentages between the weeks of the EAL session were determined for each theme. A paired-samples t-test was conducted using IBM SPSS Statistics 24 to compare these differences between the weeks of the EAL session for each theme $(p=.05)$. In addition, percentages for each theme were 


\section{Equine Assisted Learning and Emotional Safety}

determined for the total number of participants that verbalized terminology associated with a theme at some point during the entire 4-week EAL session.

\section{Results}

\section{Participation}

While all aspects of the study were voluntary, all participants were determined to be curriculum content compliant according to the self-reporting system by completing all aspects of the EAL activities during the lessons each week. No injuries of participants or horses that may have limited participation were reported during the 4-week EAL session. All students completed both the equine knowledge pretest and posttests Completion rate for the debriefing interviews was also $100 \%$.

\section{Pre- and Post-Program Test Scores}

The quantitative data analysis was utilized to track participant learning achieved through EAL as it relates to the equine science topics covered as given previously in Table 1. Overall scores for the pre- and post-program tests were recorded for each participant (Table 5). Overall scores for each participant increased from the pretest to posttest. A paired samples t-test was conducted indicating a statistically significant difference between the pretest $(M=15.0, S D=5.6)$ and posttest $(M=23.6, S D=6.6)$ scores $(p=.012)$. As for individual scores for each question, no significant differences were found between the pretest and posttest for any of the questions ( $p$ $>$.05).

Table 5. Equine Assisted Learning Participant Scores for Pretest and Posttest for Equine Knowledge Assessments in At-Risk Youths

\begin{tabular}{|l|l|l|l|l|l|}
\hline Participant & $\begin{array}{l}\text { Pretest } \\
\text { score }\end{array}$ & $\begin{array}{l}\text { Posttest } \\
\text { score }\end{array}$ & Participant & $\begin{array}{l}\text { Pretest } \\
\text { score }\end{array}$ & $\begin{array}{l}\text { Posttest } \\
\text { score }\end{array}$ \\
\hline 1 & 10 & 14 & 8 & 3 & 11 \\
\hline 2 & 9 & 13 & 9 & 20 & 30 \\
\hline 3 & 19 & 24 & 10 & 17 & 29 \\
\hline 4 & 19 & 25 & 11 & 17 & 27 \\
\hline 5 & 15 & 30 & 12 & 9 & 29 \\
\hline 6 & 16 & 25 & 13 & 19 & 26 \\
\hline 7 & 22 & 24 & & & \\
\hline
\end{tabular}




\section{Participant Interviews}

Interview responses were classified into four themes (respect, self-esteem, personal security, and connectivity) and averages of those responses within each theme for each week of the 4week EAL session were given as shown in Table 6. When comparing all theme responses between the first and last weeks of the EAL session, security had the greatest difference between the beginning and end of the 4-week EAL session $(M=-0.46, S D=0.66, p=.03)$. While scores for the other three themes were higher in week 4 compared to week 1 , no significant differences were found between the first and last weeks for respect $(M=-0.078, S D$ $=0.49, p=.58)$, connectivity $(M=-0.23, S D=0.73, p=.27)$, and self-esteem $(M=-0.46, S D$ $=0.65, p=.051)$. Although the highest percentages for personal security and connectivity were seen in week 4 , the highest percentages for respect and self-esteem were found in weeks 2 and 3, respectively. Nevertheless, comparisons between week 2 and 4 for respect $(p>.05)$ and between 3 and 4 for self-esteem $(p>.05)$ demonstrated no significant differences.

Table 6. Percentages of Weekly Emotional Safety Qualitative Responses for Equine Assisted Learning At-Risk Youth Participants

\begin{tabular}{|l|c|c|c|c|}
\hline & Respect & Self-esteem & Security & Connectivity \\
\hline Week 1 (\%) & 30.8 & 15.4 & 23.1 & 61.5 \\
\hline Week 2 (\%) & 46.2 & 23.1 & 53.8 & 69.2 \\
\hline Week 3 (\%) & 38.5 & 64.6 & 53.8 & 69.2 \\
\hline Week 4 (\%) & 38.5 & 53.8 & 61.5 & 76.9 \\
\hline
\end{tabular}

During the 4-week EAL session, $80 \%$ of participants used at least one word in at least one of their weekly interviews that described increased self-esteem. Participants used positive wording to describe themselves as "nice" or "brave." There was a peak in self-esteem language in week 3 as this was the first time the participants were able to mount and ride their horses, while in week 4 the participants had to perform more advanced riding maneuvers, which may have caused their confidence to waver. All of the participants at some point during the 4-week EAL session used language in their responses to describe improved connectivity. As one participant explained, "When my horse ran away, I knew she needed to give me space to calm down. She did not want to work with me while I was angry. I had to calm down before I could be with her. She was someone to talk to. Talking to her settled me down." For respect, $80 \%$ of participants used at least one word in the 4 weeks describing increased experiences and understanding of respect. A participant explained, "I learned to respect the horse because they wanted to be respected, like me. Respect people and horses." Language of respect peaked in week 2 as the 
participants were given a second week of practicing ground activities allowing participants to take more chances for developing respect with the horse on the ground. All participants used language in their responses to describe improved feelings of personal security during the 4week EAL session. As one participant explained, "When (the horse) got used to the rodeo, we went fast. I asked her to slow down. It made me very slow, but I decided I could do this."

\section{Discussion}

Oaklander (2018) states "The rise of animal therapy is backed by serious science showing that social support-a proven antidote to anxiety and loneliness-can come on four legs, not just two" (p. 58). The emotional support given by animals has been well document (Nicodemus, 2019), and in this study, the responses expressed by participants during interviews further support this idea. At-risk youth in this study participated in various activities from horse management to horseback riding. Each phase was designed to educate the participants about the horse and to increase the opportunity for bonding with the horse through these lesson activities. Bonding with someone, horse or human, is critical in combating loneliness, "an emerging public-health crisis," according to Heid (2018, p. 16), which can influence cognitive health including the ability to learn. In this study, through learning more about the horse, participants felt more confident to try new things with the horse, as seen in the fact that they were willing each week to participate in the next activity. All participants attended each weekly lesson and participated in all lesson activities demonstrating that despite these participants being labeled as at-risk they had a willingness to learn and a sense of ability to learn as it related to the equine activities covered in the EAL session. All participants demonstrated an improvement in equine knowledge test scores. In fact, three out of the 13 participants at least doubled their score in the posttest. Furthermore, this sense of being able to learn and confidence in their ability to learn a new activity in their lessons with the horse were reflected in the interview responses. As each week progressed, lessons covered more difficult activities with the horse, and yet, the participants were able to take what they learned from previous lessons and apply it to the next lesson starting from simply being able to catch an unfamiliar horse out in pasture to being able to confidently saddle and bridle that same horse and safely ride around the arena.

Along with the participants having the ability and willingness to achieve all of the horse activities each week and express positively their experiences with the horse in the debriefing interviews, the improvement in scores of the equine knowledge tests reflects this ability of the participants to retain these concepts successfully in this EAL environment. These scores, in 
Equine Assisted Learning and Emotional Safety

addition to the participants' ability to safely perform each weekly equine activity, indicate that the equine science content covered in the EAL session was comprehended and this was achieved meeting once a week for only 4 weeks. The ability to retain and apply this knowledge each week during the equine activities suggests that experiential learning can occur within the EAL environment (Geller \& Porges, 2014; National Center for Safe Supportive Learning Environments, 2018).

Furthermore, for at-risk youth, it is difficult to create an emotionally safe environment where they can successfully learn. The significant improvement in personal security percentages in conjunction with the increase in equine knowledge scores by the end of the 4-week session indicates that the equine environment utilized for EAL may offer an alternative approach besides the classroom for at-risk youth. However, the absence of significant increases through the EAL session for all themes including the drop in respect and self-esteem percentages after week 2 and week 3, respectively, warrants further investigation. Nevertheless, the results found in this study are supported by Evans et al. (2019). In that study, the use of the equine environment was utilized for college students enrolled in an equine assisted therapy course in which these students demonstrated both an improvement of knowledge and confidence by the end of the semester-long course. Furthermore, Hammer, Bach-Gorman, and Berg (2019) reported that college students participating in an equine assisted counseling program showed improvement in anxiety levels and in feelings of belonging within their community by the end of a 7-week session. Both of these studies reflect improvements in themes associated with emotional safety through the interaction of the horse. In the end, these issues associated with at-risk youth are prevalent in the academic setting and are deterrents to the academic success of students (Reilly, 2018), thus, the use of the horse as a tool for the educational system may be a promising alternative to traditional educational methodology.

Positive outcomes have come out of programs where horses were used as instruments to intervene in social, emotional, and physical therapies (Maujean et al., 2013; Ward, et al., 2013). EAL, specifically, has been documented to improve social connectivity, communication amongst peers, and self-esteem issues found within participants (Kendall \& Maujean, 2015). Research suggests interventions such as EAL targeting emotional safety affect long term daily aspects of life in addition to immediate results (Bass et al., 2009; Ward, et al., 2013). As for this study, although participants were not tracked after the session, throughout the program, as participants interacted with horses, they demonstrated realization and growth in regard to perceived personal value and abilities, particularly in the area of personal security as reflected in their interview statements. Interestingly, despite the difficulty of the tasks as the participants 
Equine Assisted Learning and Emotional Safety

progressed each week, all participants were willing to attempt each activity and were able to complete it, even though participants knew that participation in the equine activity was voluntary. Thus, participants were content compliant throughout the 4-week EAL session. No absences were recorded for any of the participants throughout the 4-week session, and each activity presented in each weekly lesson was attempted by all participants. The participation success seen in this study is unique from other outdoor experiential therapy programs for youth where issues of participation have been reported (Buning et al., 2015).

As each horse and human pair completed activities or challenges, participants expressed wording that was associated with joy as it related to the equine activities they were performing along with a sense of accomplishment. As accomplishments were achieved by completing the required tasks each lesson, personal security and connectivity were reinforced as expressed in the participants' interviews. This same sense of confidence has been reported in college students as they completed an equine assisted therapy course (Evans et al., 2019). Emotional safety demonstrated improvement with all four themes at various points in the 4-week session, and while only security showed a significant difference by week 4, connectivity showed a gradual increase throughout the 4-week session that could be strengthened by larger numbers of participants. While a drop in percentages was documented for respect and self-esteem after the second and third weeks of the EAL session, respectively, during which riding activities were presented, an improvement in percentages might have occurred if the EAL program had continued past 4 weeks. Additional weeks added to the 4-week EAL session would have allowed for participants to become more comfortable with riding activities, and, in turn, improve feelings of respect and self-esteem. In both the studies by Evans et al. (2019) and by Hammer et al. (2019), college students participated in equine assisted activities for more than 4 weeks giving participants more time to become accustomed to equine activities, especially those more challenging for the student, such as riding the horse.

Along with the shortened timeframe for the EAL session, another limitation to this study is that it does not track the participants after the 4-week session. Further research should evaluate youth after their participation in the EAL session to determine whether EAL has a lasting positive impact without the presence of the horse. In addition, future studies should track learning success outside of the equine environment while the youth are actively participating in EAL to see if the learning success seen in the equine knowledge test scores is translating to their academics in the classroom environment. Benton et al. (2019) surveyed parents of children participating in an equine assisted therapy program finding that outside of the equine 
Equine Assisted Learning and Emotional Safety

environment youths participating in these programs for greater than 10 weeks demonstrated an improvement in their overall cognitive abilities.

Unfortunately, drawing a direct relationship between development of equine knowledge and emotional safety is restricted by the qualitative approach utilized in this study for assessing emotional safety through the interview process. Nevertheless, a recent study utilizing a quantitative measure for emotional safety demonstrated a relationship between learning and emotional safety within animal science coursework in college students (Cagle-Holtcamp et al., 2019). However, the survey instrument utilized by Cagle-Holtcamp et al. (2019) had a limiting response rate, thus, with an already small sample size in this study it was a concern whether response rates within the at-risk youth population would drop with the use of a survey instrument. As reported in Evans et al. (2019), response rates of college students participating in an EAT program that used a survey instrument dropped to just over half (58.6\%) for the final survey, which is in contrast to the $100 \%$ response rate seen in this study using a qualitative measure. With the smaller sample size used in this study a higher response rate was necessary for interpretation of the data. In addition, to evaluate curriculum content, researchers sought to get more specific details of activities where youth demonstrated the themes of emotional safety. However, due to the use of the qualitative method, this study did not carry out further statistical analysis concerning the correlations between topic area and a specific theme. All observations concerning content were anecdotal. Nevertheless, it is interesting to note the rise in self-esteem as the youth got a chance to ride their horses for the first time in the third week of the EAL session.

Although it was insignificant, there was a drop in self-esteem from week 3 to week 4, which could be due to the introduction of more advanced riding maneuvers covered in week 4 . Similarly, the rise in respect at week 2 corresponded with the youths performing more challenging ground activities. These ground activities may have been empowering for them, but this feeling of respect dropped in week 3 when the participants rode their horses for the first time. It might have been possible to better explain this drop in respect and self-esteem at different weeks in the 4-week EAL session using a quantitative measure, which would allow for more statistical analysis investigating more concrete aspects of the activity that may have initiated this drop in responses specific to these themes. Nevertheless, in the end, overall improvements in themes, the positive nature of all of the interviews, the improved knowledge of equines by the end of the session, and the $100 \%$ participation in all activities for each lesson suggest program activities were beneficial to this specific population. A larger sample of the population and the use of a quantitative analysis method for measuring the themes of 
emotional safety may assist in strengthening conclusions and give further insight into specific impacts of certain aspects of the EAL session.

\section{Conclusion}

Early intervention assisting youth who are at risk is critical for academic success, and this intervention should include creating an emotionally safe environment that promotes learning. This study is the first step in understanding EAL and its potential for positive intervention in the emotional safety of those youth labeled at-risk. By learning each week the basics of horse behavior, management, handling, and riding, and building each week on lessons learned, the youth participants gained an understanding of their equine partners, and, in turn, developed a willingness to face new, more challenging activities with their equine partners as the EAL session progressed. This interaction with the horse through EAL created an emotionally safe environment for learning. In the end, this program design will potentially aid in developing future EAL curriculum needed to assist programs that seek to provide services to at-risk youth and lay the foundation for future assessment protocols for measurement of emotional safety.

\section{Acknowledgements}

This research was funded by a USDA-NIFA AFRI Fellowship Grant. Acknowledgement is given to the staff of the Mississippi State University Extension Equine Assisted Therapy Programs for facilitation of the equine assisted learning session.

\section{References}

AgriLife Extension. (2013). Texas 4-H horse quiz bowl supplement. Texas A\&M System. Retrieved from http://texas4-h.tamu.edu/wp-content/uploads/Horse-Quiz-Bowl-Supplement.pdf

Bachi, K., Terkel, J., \& Teichman, M. (2012). Equine-facilitated psychotherapy for at-risk adolescents: The influence on self-image, self-control and trust. Clinical Child Psychology and Psychiatry, 172), 298-312. doi:10.1177/1359104511404177

Bass, M. M., Duchowny, C. A., \& Llabre, M. M. (2009). The effect of therapeutic horseback riding on social functioning in children with autism. Journal of Autism and Developmental Disorders, 39(9), 1261-1267. doi:10.1007/s10803-009-0734-3

Benton, S., Petr, L., Schneider, L., \& Ivey, J. (2019). Effects of therapeutic riding on parental perceptions of mental and physical disability improvement. Journal of Equine Veterinary Science, 76, 115.

Bird, C. (1996). Mutual respect and neutral justification. Ethics, 1071), 62-96. 
Equine Assisted Learning and Emotional Safety

Borgi, M., Loliva, D., Cerino, S., Chiarotti, F., Venerosi, A., Bramini, M., . . . Cirulli, F. (2016).

Effectiveness of a standardized equine-assisted therapy program for children with autism spectrum disorder. Journal of Autism and Developmental Disorders, 46(1), 1-9. doi:10.1007/s10803-015-2530-6

Brandt, C. (2013). Equine-facilitated psychotherapy as a complementary treatment intervention. The Practitioner Scholar: Journal of Counseling and Professional Psychology, 2(1), 23-42.

Buning, R. J., Coble, C., \& Kerwin, S. (2015). The progressive involvement of youth in niche sport: the perspective of youth participants and their parents. Journal of Amateur Sport, 1(1), 52-80. doi:10.17161/jas.v1i1.4921

Burgon, H. L. (2011). 'Queen of the world': Experiences of 'at-risk' young people participating in equineassisted learning/therapy. Journal of Social Work Practice, 25(2), 165-183. doi:10.1080/02650533.2011.561304

Burgon, H. L. (2014). Equine-assisted therapy and learning with at-risk young people. London, UK: Palgrave Macmillan.

Cagle-Holtcamp, K., Nicodemus, M., Gilmore, A., Christiansen, D., Galarneau, K., Phillips, T., ... Sansing, W. (2019). Relationship between development of equine knowledge and feelings of emotional safety in college students enrolled in animal science courses [Abstract]. Journal of Equine Veterinary Science, 76, 111.

Certified Horsemanship Association. (2008). Horsemanship manual: Composite level 1, level 2, level 3, and level 4. Lexington, KY: Author.

Crocker, J., Luhtanen, R. K., Cooper, M. L., \& Bouvrette, A. (2003). Contingencies of self-worth in college students: theory and measurement. Journal of Personality and Social Psychology, 85(5), 894. doi:10.1037/0022-3514.85.5.894

Eagala. (2019). The global standard for equine assisted psychotherapy \& personal development [Video]. Available from https://www.eagala.org

Evans, H., Nicodemus, M., Irvin, L., Brunson, C., Beckman, L., Memili, E., \& Jousan, D. (2019). Volunteer impact in an equine assisted therapy program on confidence and knowledge in college students. Journal of Equine Veterinary Science, 76, 110. doi:10.1016/j.jevs.2019.03.164

Geller, S. M., \& Porges, S. W. (2014). Therapeutic presence: Neurophysiological mechanisms mediating feeling safe in therapeutic relationships. Journal of Psychotherapy Integration, 24(3), 178. doi:10.1037/a0037511

Hall, T. M., Schaefer, C. E., \& Kaduson, H. G. (2002). Fifteen effective play therapy techniques. Professional Psychology: Research and Practice, 33(6), 515-522. doi:10.1037//07357028.33.6.515 
Journal of Youth Development | http://jyd.pitt.edu/ | Vol. 14 Issue 4 DOI 10.5195/jyd.2019.727 Equine Assisted Learning and Emotional Safety

Hammer, C. J., Bach-Gorman, A. R., \& Berg, E. I. (2019). Equine-assisted counseling as an intervention for undergraduate female college students experiencing anxiety. Journal of Equine Veterinary Science, 76, 118. doi:10.1016/j.jevs.2019.03.183

Harris, G. (2011, March 5). Talk doesn't pay, so psychiatry turns instead to drug therapy. New York Times, 6.

Heid, M. (2018, October 12). The loneliness epidemic. Time, Special Edition, Mental Health: A New Understanding, 16-21.

Henderson, K. A., Whitaker, L. S., Bialeschki, M. D., Scanlin, M. M., \& Thurber, C. (2007). Summer camp experiences: Parental perceptions of youth development outcomes. Journal of family issues, 28(8), 987-1007.

Hopper, T. D., \& Iwasaki, Y. (2017). Engagement of "at-risk" youth through meaningful leisure. Journal of Park \& Recreation Administration, 35(1), 20-31. doi:10.18666/JPRA-2017-V35-I1-7289

Kagan, J. (2009). Loneliness: Human nature and the need for social connection [Review of the book Loneliness: Human nature and the need for social connection by J. Cacioppo \& W. Patrick]. American Journal of Psychiatry, 166(3), 375-376. doi:10.1176/appi.ajp.2008.08091320

Kendall, E., \& Maujean, A. (2015). Horse play: A brief psychological intervention for disengaged youths. Journal of Creativity in Mental Health, 10(1), 46-61. doi:10.1080/15401383.2014.962720

Lentini, J. A., \& Knox, M. S. (2015). Equine-facilitated psychotherapy with children and adolescents: An update and literature review. Journal of Creativity in Mental Health, 10(3), 278-305. doi:10.1080/15401383.2015.1023916

Letiecq, B. L., Bailey, S. J., \& Keller, J. A. (2007). Rural after-school programs: Meeting the needs of atrisk youth and their families. Journal of Youth Development, 2(2), 56-73. doi:10.5195/jyd.2007.346

Lutz, K. (2010). Horsemanship/humanship skills: how horses make us better people. Retrieved from PATH Intl. website: https://www.pathintl.org/images/pdf/conferences/national/ presentations\%20for\%20web/2011/Horsemanship-Humanship-Skills.pdf

McCann, A. (2018, July 17). States with the Most At-Risk Youth. WalletHub. Retrieved from https://wallethub.com/edu/states-with-the-most-at-risk-youth/37280/

Maujean, A., Kendall, E., Lillan, R., Sharp, T., \& Pringle, G. (2013). Connecting for health: Playing with horses as a therapeutic tool. Journal of Community Psychology, 41(4), 515-522. doi:10.1002/jcop.21547

National Center for Safe Supportive Learning Environments (2018). Emotional safety. Retrieved from https://safesupportivelearning.ed.gov/topic-research/safety/emotional-safety.

Nicodemus, M. C. (2019). Companion animal management: A guide to pet selection \& care. Dubuque, IA: Kendall Hunt. 
Journal of Youth Development | http://jyd.pitt.edu/ | Vol. 14 Issue 4 DOI 10.5195/jyd.2019.727

Equine Assisted Learning and Emotional Safety

Oaklander, M. (2018, October 12). Your pets are good for your health. Time, Special Edition, Mental Health: A New Understanding, 58-59.

Odendaal, J. S. (2000). Animal-assisted therapy-magic or medicine?. Journal of Psychosomatic Research, 49(4), 275-280. doi:10.1016/S0022-3999(00)00183-5

Paone, T.R., Packman, J., Maddox, C., \& Rothman, T. (2008). A school-based group activity therapy intervention with at-risk high school students as it relates to their moral reasoning. International Journal of Play Therapy, 17(1), 122-137. doi:10.1037/a0012582

PATH, Intl. (2017). EAAT Definitions. Retrieved from http://www.pathintl.org/resourceseducation/resources/eaat/193-eaat-definitions

Reilly, K. (2018, October 12). Depression on campus. Time, Special Edition, Mental Health: A New Understanding, 28-31.

Ruiz, F. J. (2012). Acceptance and commitment therapy versus traditional cognitive behavioral therapy: A systematic review and meta-analysis of current empirical evidence. International Journal of Psychology and Psychological Therapy, 12(3), 333-357.

Ryon, S. B., Early, K. W., \& Kosloski, A. E. (2017). Community-based and family-focused alternatives to incarceration: A quasi-experimental evaluation of interventions for delinquent youth. Journal of Criminal Justice, 51, 59-66. doi:10.1016/j.jcrimjus.2017.06.002

Saunders-Ferguson, K., Barnett, R. V., Culen, G., \& TenBroneck, S. (2008). Self-esteem assessment of adolescents involved in horsemanship activities. Journal of Extension, 46(2).

Short, M. E., Goetzel, R. Z., Pei, X., Tabrizi, M. J., Ozminkowski, R. J., Gibson, T. B., . . Wilson, M. (2009). How accurate are self-reports? An analysis of self-reported healthcare utilization and absence when compared to administrative data. Journal of Occupational and Environmental Medicine/ American College of Occupational and Environmental Medicine, 51(7), 786-796. doi:10.1097/JOM.0b013e181a86671.

Thomas, L., Lytle, M., \& Dammann, B. (2016). Transforming therapy through horses: Case stories of teaching the EAGALA model in action. Santaquin, UT: Eagala.

Ward, S. C., Whalon, K., Rusnak, K., Wendell, K., \& Paschall, N. (2013). The association between therapeutic horseback riding and the social communication and sensory reactions of children with autism. Journal of Autism and Developmental Disorders, 43(9), 2190-2198. doi:10.1007/s10803013-1773-3

Wilson, S. J., \& Lipsey, M. W. (2000). Wilderness challenge programs for delinquent youth: A metaanalysis of outcome evaluations. Evaluation and Program Planning. 23(1), 1-12. doi:10.1016/S0149-7189(99)00040-3 